\title{
Trajectory of the COVID-19 pandemic: chasing a moving target
}

\author{
Kamal Kant Sahu ${ }^{1}$, Ajay Kumar Mishra ${ }^{1}$, Amos Lal $^{2 \wedge}$ \\ ${ }^{1}$ Department of Internal Medicine, Saint Vincent Hospital, Worcester, Massachusetts, USA; ${ }^{2}$ Division of Pulmonary and Critical Care Medicine, \\ Mayo Clinic, Rochester, Minnesota, USA \\ Contributions: (I) Conception and design: All authors; (II) Administrative support: None; (III) Provision of study materials or patients: All authors; \\ (IV) Collection and assembly of data: All authors; (V) Data analysis and interpretation: All authors; (VI) Manuscript writing: All authors; (VII) Final \\ approval of manuscript: All authors. \\ Correspondence to: Amos Lal, MBBS, MD. Division of Pulmonary and Critical Care Medicine, Mayo Clinic, Rochester, Minnesota 55902, USA. \\ Email: Lal.Amos@mayo.edu; manavamos@gmail.com.
}

\begin{abstract}
The spread of COVID-19 has already taken a pandemic form, affecting over 180 countries in a matter of three months. The full continuum of disease ranges from mild, self-limiting illness to severe progressive COVID-19 pneumonia, multiorgan failure, cytokine storm and death. Younger and healthy population is now getting affected than before. Possibilities of airborne and fecal oral routes of transmission has increased the concern. In the absence of any specific therapeutic agent for coronavirus infections, the most effective manner to contain this pandemic is probably the non-pharmacological interventions (NPIs). The damage due to the pandemic disease is multifaceted and crippling to economy, trade, and health of the citizens of the countries. The extent of damage in such scenarios is something that is beyond calculation by Gross Domestic Product rate or currency value of the country. Unfortunately, unlike many other diseases, we are still away from the target antiviral drug and vaccine for severe acute respiratory syndrome (SARSCoV-2) infection. The prime importance of NPIs like social distancing, staying in home, work from home, self-monitoring, public awareness, self-quarantine, etc. are constantly being emphasized by CDC, WHO, health ministries of all countries and social media houses. This is time of introspection and learning from our mistakes. Countries like China and South Korea who were initially the most hit countries could contain the disease spread by liberal testing of their population, stringent quarantine of people under investigation and isolation of the positive cases. Rest of the countries need to act urgently as well to bring an immediate halt in the community transmission.
\end{abstract}

Keywords: COVID-19; coronavirus; pandemic; infection; vaccine

Submitted Mar 23, 2020. Accepted for publication May 18, 2020.

doi: $10.21037 /$ atm-20-2793

View this article at: http://dx.doi.org/10.21037/atm-20-2793

\section{Introduction}

Wuhan, a city in Hubei province of Eastern China has an approximate population of 11 million people. As per epidemiologists, this city is considered as an epicenter for current COVID-19 pandemic (1,2). Subsequently, it involved other parts of China and then to the rest of the world. As of $19^{\text {th }}$ March 2020, there are 244,979 confirmed cases in 180 countries with 10,035 deaths (3). Worst hit countries are China, Italy, South Korea, Iran, France, Spain, Germany and many other European countries (Figure 1). Italy surpassed China on $19^{\text {th }}$ March 2020 in terms of having the highest number of active COVID-19 cases and more deaths (3).

^ORCID ID: 0000-0002-0021-2033. 


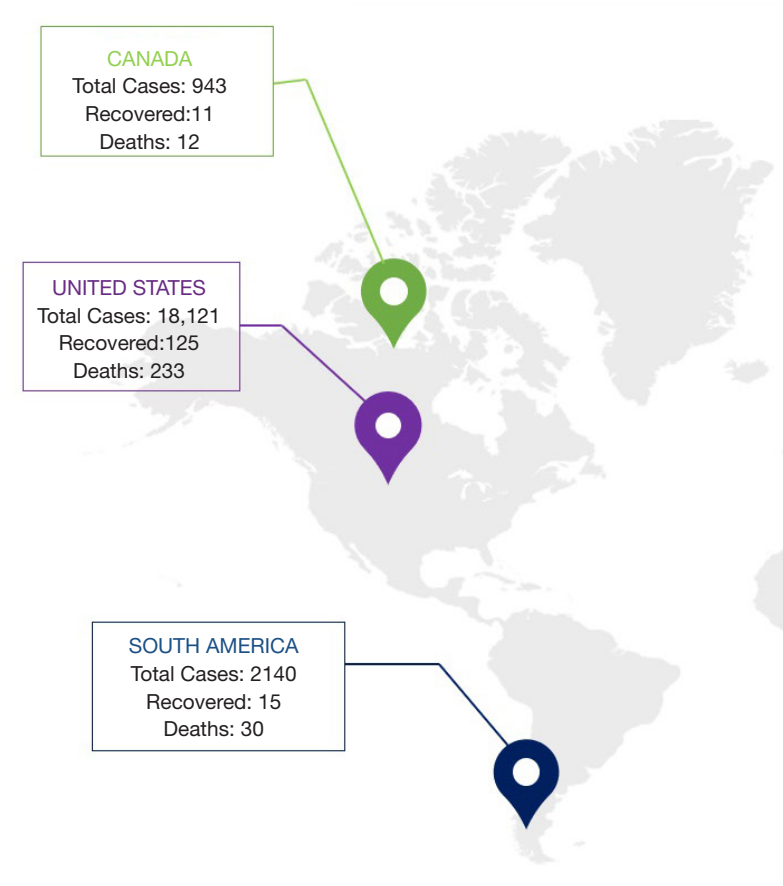

Figure 1 COVID-19 pandemic burden worldwide.

\section{Disease background}

\section{Coronavirus family}

Severe acute respiratory syndrome (SARS-CoV-2) belongs to the family of Beta coronavirus which also has coronaviruses responsible for previous outbreaks-SARS and the Middle East respiratory syndrome (MERS) outbreaks.

\section{Possible routes of transmission}

In the initial phase, most COVID-19 cases in China were found to have a direct or indirect link to Huanan Seafood Market in Wuhan, possibly due to the zoonotic spill over from wild animals to the humans (4). Gradually, as the transmission passed beyond $1^{\text {st }}$ and $2^{\text {nd }}$ generations, more cases were reported to have no direct link with the animal exposure and were instead related to community transmission from person to person (5). Currently, there is enough evidence to suggest that respiratory droplets and direct contact with contaminated surfaces are the two most common routes of SARS-CoV-2 transmission. Just like in many endemic diseases, other possible routes like airborne or faecal oral transmission is being explored for SARSCoV-2 transmission $(6,7)$. Now with each passing day, most of the COVID-19 cases are as a result of "community spread" which means SARS-CoV-2 virus seems to be easily sustaining and spreading in the community with most of the affected population unaware of how or from where they became infected.

\section{Demographic details of the patients}

SARS-CoV-2 viral infection can affect any individual in a naïve susceptible population. Most retrospective studies had cohort with age range between $50-80$ s $(8,9)$. In addition to this, there are also studies reporting no deaths in those under age 30 from Korea or under age 50 from Japan (5). These results were falsely perceived or at least fail to alert the younger population especially the so called "millennial generation" individuals, most of them started thinking that they are immune to this virus. The sense of false security and illusion did not persist long enough as now we have concrete data from United States (US) that harbours close to 20,000 COVID-19 cases. As per The Centres for Disease Control and Prevention (CDC), more younger patients in US are catching SARSCoV-2 infection. In their report dated $20^{\text {th }}$ March 2020, CDC mentions that $20 \%$ of the hospitalized patients and 
$12 \%$ of the intensive care patients from US belong to age range of 20 to 44 years (10). Amongst the comorbidities, hypertension, cardiovascular disorders, cerebrovascular disorders and diabetes are the top medical conditions who had more severe disease and required intensive care as compared to individuals without these comorbidities (7-16). Specific subset of population like patients suffering from cancer, transplant recipients or other benign blood disorders need special attention for their underlying disease (17-20).

\section{Symptomatology and laboratory investigations}

\section{Symptomatology and Mortality rate of COVID-19 cases}

In general, most SARS-CoV-2 affected patients have only mild symptoms, with approximately $20 \%$ developing moderated to severe illness (21). This means that most patients can be managed with home quarantine only and hospital isolation is required only for moderate to sick population. The likelihood of having more severe disease is multifactorial. Vulnerable population as per the available literature are older individuals more than 60 years, pregnant women, patients with multiple comorbidities and immunosuppressed individuals like cancer patients (1,20,22-28). With regards to the gender predisposition, there are mixed reports with some mentioning that males have higher chance of acquiring the infection with higher mortality rates when compared to females. The age subgroup which has the highest mortality are the older individuals as compared to the younger population. The Special Expert Group for Control of the Epidemic of Novel Coronavirus Pneumonia of the Chinese Preventive Medicine Association has recently reported the epidemiological characteristics of COVID-19 cases $(29,30)$. As per the report, the overall crude morality rate was $2.3 \%$, with $14.8 \%$ in the age group over 80 years old, $2.8 \%$ in men and $1.7 \%$ in women. Individuals with HIV, hematopoietic stem cell transplantation, pregnancy is always at risk of acquiring atypical viral infections and hence such patients have higher chance to acquire COVID-19 disease (31-35). The most common reported symptoms were high grade fever, dry cough, shortness of breath and fatigue as the most common presenting features. Nausea, vomiting and other gastrointestinal symptoms were rarely reported. Recent reports have shown that patients with severe COVID-19 had higher cardio-cerebrovascular events than the milder cases $(36,37)$.

\section{Blood work and their significance}

Laboratory studies including complete blood count, renal function test, liver function test, coagulation profile, D dimer, serum calcitonin are the common lab tests for hospitalised COVID-19 patients. Various inflammatory markers like C-reactive protein (CRP), procalcitonin, ferritin, D-dimer, interleukin 2 (IL-2) are shown to be elevated in patients with COVID-19 and have been found to be associated with vital organs dysfunction $(38,39)$. Wang et al. in their case series of 138 hospitalised patients reported following laboratory abnormalities: lymphopenia (70.3\%), deranged coagulogram (58\%), elevated lactic acid dehydrogenase $(39.9 \%)$ and abnormal imaging findings (100\%). Presence of lymphopenia, elevated D dimer values, deranged renal functions have been reported as poor prognostic factors with high chance of need of intensive care with high mortality $(7,8)$. Other hematological parameters like thrombocytopenia has been found to be predicting the severity and worst prognosis $(40,41)$.

\section{Diagnostic modalities: how to investigate a suspected case?}

\section{COVID-19 RT-PCR testing}

Amongst the available investigations, the COVID-19 realtime reverse transcription polymerase chain (RT-PCR) test is used for the qualitative detection of nucleic acid from SARS-CoV-2 virus. Samples can be used taken from upper or lower respiratory areas like swabs, sputum, lower respiratory tract aspirates, and bronchoalveolar lavage. It is important to note that a positive COVID-19 result by RTPCR does not rule out the concomitant bacterial infection or other viral infections at the same time. Similarly, a negative result does not exclude SARS-CoV-2 infection altogether and hence must not be used as a sole parameter for diagnostic purposes. Hence, we emphasize that if clinical suspicion is high, the ideal approach should be to evaluate the suspected patient based on the combination of clinical symptoms, contact history, and other dynamic blood changes to identify COVID-19. CDC as laid down guidelines on how to interpret the results and suggested on repeating the test in case the of high clinical suspicion after consultation with public health authorities (Table 1) (42).

\section{Computed tomography (CT imaging) of the chest}

As mentioned above, if clinically indicated, imaging studies 
Table 1 Interpretation of COVID-19 RT-PCR test based on CDC guidelines

\begin{tabular}{|c|c|c|c|c|c|}
\hline $\begin{array}{l}\text { 2019-nCoV_N1 } \\
\text { combined primer }\end{array}$ & $\begin{array}{l}\text { 2019-nCoV_N2 } \\
\text { combined primer }\end{array}$ & $\begin{array}{l}\text { Human RNase } \\
\text { P gene (RP) }\end{array}$ & $\begin{array}{l}\text { Result } \\
\text { interpretation }\end{array}$ & Report & Actions \\
\hline Positive & Positive & $\begin{array}{l}\text { Positive or } \\
\text { negative }\end{array}$ & $\begin{array}{l}\text { 2019-nCoV } \\
\text { detected }\end{array}$ & Positive 2019-nCoV & Report results to CDC and sender \\
\hline Positive & Negative & $\begin{array}{l}\text { Positive or } \\
\text { negative }\end{array}$ & Inconclusive result & Inconclusive & $\begin{array}{l}\text { Repeat testing of nucleic acid and/ } \\
\text { or re-extract and repeat rRT-PCR } \\
\text { If the repeated result remains } \\
\text { inconclusive, contact State Public } \\
\text { Health Laboratory or CDC for } \\
\text { instructions for transfer of the } \\
\text { specimen or further guidance }\end{array}$ \\
\hline Negative & Positive & $\begin{array}{l}\text { Positive or } \\
\text { negative }\end{array}$ & Inconclusive result & Inconclusive & $\begin{array}{l}\text { Repeat testing of nucleic acid and/ } \\
\text { or re-extract and repeat rRT-PCR } \\
\text { If the repeated result remains } \\
\text { inconclusive, contact State Public } \\
\text { Health Laboratory or CDC for } \\
\text { instructions for transfer of the } \\
\text { specimen or further guidance }\end{array}$ \\
\hline Negative & Negative & Negative & Negative & Invalid & $\begin{array}{l}\text { Repeat extraction and rRT-PCR } \\
\text { If the repeated result remains } \\
\text { invalid, consider collecting a new } \\
\text { specimen from the patient }\end{array}$ \\
\hline Negative & Negative & Positive & $\begin{array}{l}\text { 2019-nCoV not } \\
\text { detected }\end{array}$ & Not detected & $\begin{array}{l}\text { Report results to sender } \\
\text { Consider testing for other } \\
\text { respiratory viruses }\end{array}$ \\
\hline
\end{tabular}

like computed tomography (CT) of the chest should be done to evaluate the patient's low respiratory symptoms $(43,44)$. Ai et al. did a comparative study involving 1,014 patients, to compare CT imaging with RT-PCR for their sensitivity (45). They found that $88 \%(888 / 1,014)$ had positive chest CT scans while only $59 \%(601 / 1,014)$ had positive RT-PCR results. Classical positive CT findings included groundglass opacities (GGOs), local patchy shadowing, bilateral patchy shadowing, or interstitial abnormalities. Fang et al. also had similar finding in their series of 51 patients, the sensitivity of CT was $98 \%$ compared to RT-PCR of $71 \%$ $(\mathrm{P}<0.001)$ (46). While, it is gratifying to know that CT scan could complement RT-PCR for its higher sensitivity, however we should also acknowledge that there might be no radiographic abnormality in less severe cases or in those cases who present early to hospital $(43,47,48)$. Guan et al. did not find any CT abnormality in 157 of 877 patients $(17.9 \%)$ with no severe disease and in 5 of 173 patients (2.9\%) with severe disease. On similar lines, report by
Bernheim et al. on 121 symptomatic COVID-19 patients, suggested that 27 (22\%) had normal CT findings at initial presentation (48). They studied these patients at follow up as well with a repeat CT scan and found that with a longer time after the onset of symptoms, more patients had positive CT findings including consolidation, bilateral and peripheral disease, and GGOs (48). Lastly, this is to note that there are no pathognomonic radiological features that can confidently differentiate COVID-19 from other causes of lung infiltrates (49-54).

\section{Trajectory of COVID-19 pandemic: how different countries are tackling?}

\section{Rise of the pandemic: when to act and how to act?}

In most cases, a pandemic disease goes through the typical phases of spread from a local outbreak $\rightarrow$ nationwide epidemic $\rightarrow$ pandemic worldwide steps. Depending on the region of outbreak, few regions or countries might not get 
time to prepare themselves to act efficiently and promptly unless their taskforce is already on toes by default, while other distant countries where the disease has still not reached may get some time to prepare themselves. The damage due to the pandemic disease is multifaceted and crippling to economy, trade, and health of the citizens of the countries. The extent of damage in such scenarios is something that is beyond calculation by Gross Domestic Product rate or currency value of the country. That is why it is important to learn from past experiences of outbreaks and have a framework/guideline set before hand with regular mock drilling from time to time to ensure they are constantly validated and updated. For instance, countries like Singapore, and Japan who have successfully contained the current COVID-19 pandemic have learned a good lesson from SARS epidemic back in 2003 when they made stringent guidelines.

\section{How to flatten the curve: "suppression" versus "mitigation", which one is better?}

Comparing the trajectory of COVID-19 pandemic of various countries is a litmus test of the extent of preparedness of various countries and public awareness. An infectious pandemic like COVID-19 can be tackled in two ways: (I) suppression strategy, which focuses to reverse epidemic growth; (II) mitigation strategy, which stresses more on slowing than stopping epidemic spread.

* Suppression strategy and its feasibility. Although initially China and South Korea were heavily struck by COVID-19, but with their suppression strategy, which is an intense intervention model, these two countries are able to flatten their respective curves of COVID-19 pandemic. China, and South Korea have followed the "suppression protocol" by locking down their major cities, social distancing the entire population, case isolation, home quarantine and by closing schools and universities. The most challenging aspect of suppression strategy is the relapse with appearance of new cases as soon as suppression loosens. Probably this is the reason that we are still seeing the pockets, or a cluster of cases being reported from these countries. The "generous screening strategy" allowed South Korea to accurately estimate the COVD-19 burden to guide them. They subsequently took a massive task, implemented a nationwide public health measures along with strict lockdown of cities and legal penalties against the law breakers which helped them timely mitigate the spread of virus.

* Mitigation strategy and its effectiveness. Singapore has a well-established framework in place: the MOH Disease Outbreak Response System which always keeps Singapore on toes and has a generic preparedness model and response plan against any outbreak. The Disease Outbreak Response System Condition (DORSCON) framework is a colourcoded alert, risk assessment and response action protocol which comes into action as soon there is an outbreak. It was the promptness by this framework that Singapore did not require a suppression strategy and were able to successfully control the pandemic at stage 2 level itself.

\section{Italy, conceding the worst hit so far: what went wrong?}

As mentioned above, China, South Korea and Singapore were able to efficiently implement their personalised containment measures which could have reduced number of deaths by thousands at least if not tens of thousands. Italy's health infrastructure is otherwise quite impressive with 3.2 hospital beds per 1,000 people in contrast 2.9 in the United Kingdom.

Initially, Italy did respond promptly and efficiently to COVID-19 pandemic, but its national health capacity system soon got saturated. Within the first three weeks of $1^{\text {st }}$ COVID-19 case detection in Italy, patients flooded the hospitals, occupied the ICU beds and ventilators clogging the healthcare resources (54). The most inflicted regions are in northern Italy (Figure 2). The northern regions like Lombardia (22,264 total COVID-19 cases), EmiliaRomagna (5,968 total COVID-19 cases) and Veneto (4,031 total COVID-19 cases) have so far seen the most cases and deaths, where overloaded hospitals are groaning to cope $(55,56)$.

Italy's death toll is skyrocketing since then and even surpassed China's numbers on $19^{\text {th }}$ March 2020 (56). Rosenbaum et al. in his recent report discussed Italy's ground situations at all fronts of Ethics, Logistics, and Therapeutics (57). Grasselli et al. from University of Milan, Italy in their report outlined in detail the actions taken by an emergency task force set up by the Government of Lombardy, Italy in association with local health authorities on $21^{\text {st }}$ February 2020 , when a cluster of 16 cases were reported (58). A team of 15 first-responder hub hospitals were allocated for their expertise in infectious disease 


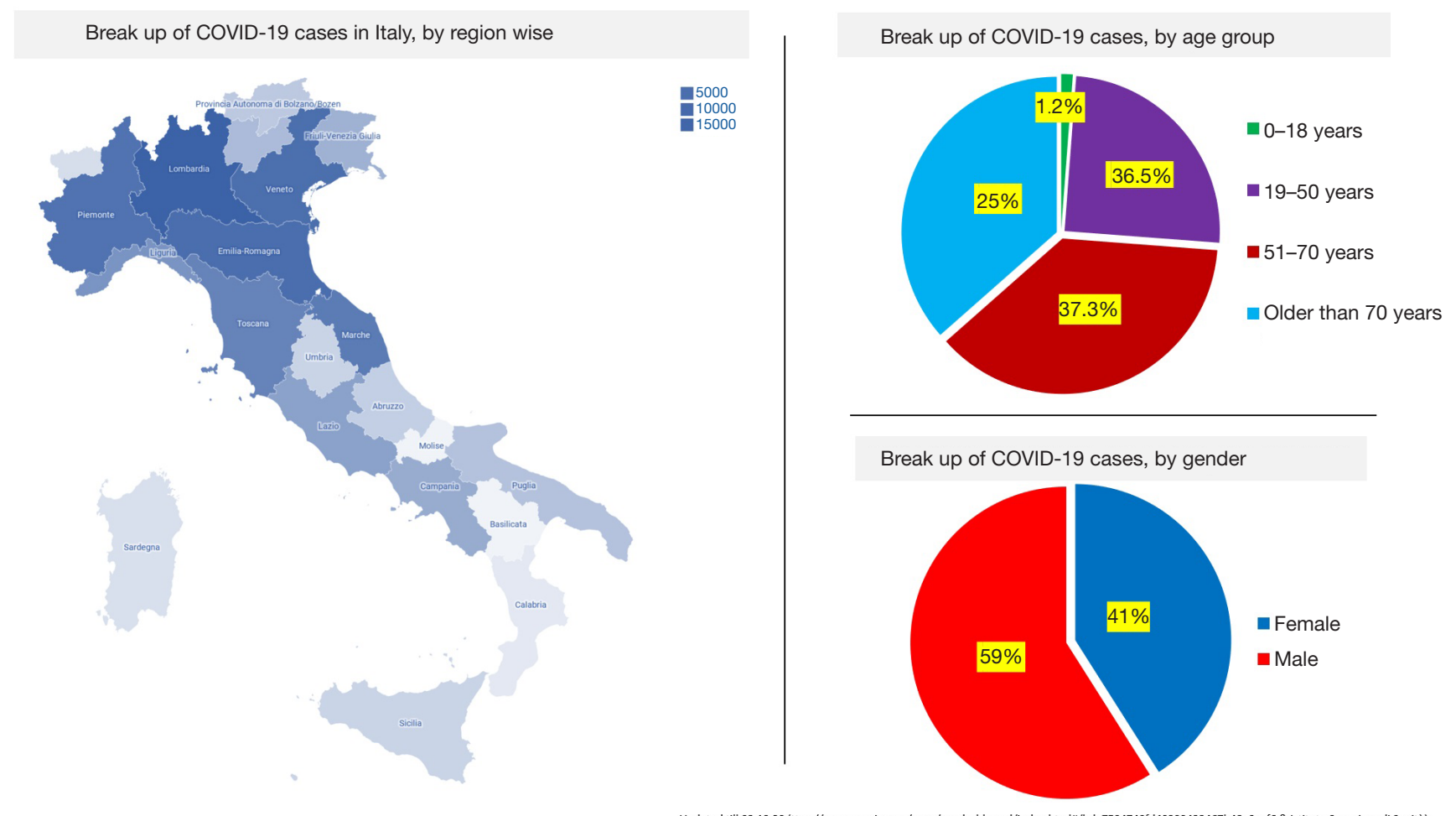

Figure 2 Heat map of COVID-19 burden in Italy in various regions with breakdown of cases based on gender and age group.

or because they were under part of the Venous-Venous ECMO Respiratory Failure Network (RESPIRA). Extra ICU beds were created to accommodate the sick patients. However, despite the best efforts, most of the hospitals got overwhelmed and ran out of their maximum capacity to handle the critical patients. A health resource and service assessment were done by the end of two weeks (dated $7^{\text {th }}$ March 2020) which revealed a huge inequality between the formulation and actuality faced by Italy $(47,59)$. As per Grasselli et al.'s report, the patient sickness profiles and health resource mobilisation for what Italy prepared itself was based on that data from China and Singapore experiences that witnessed approximately $5 \%$ ICU admission rate amongst the COVID-19 hospitalised patients (58). In contrast, when COVID-19 pandemic hit Italy, it was found that there were approximately $12 \%$ of the total COVID-19 cases, and $16 \%$ of all hospitalized patients who required ICU admissions. These ICU admission numbers were actually $2-3$ times of what Italy anticipated while formulating its taskforce. Considering the collapsing intensive care infrastructure of almost all the hospitals, on $6^{\text {th }}$ March 2020, The Italian College of Anesthesia, Analgesia, Resuscitation and Intensive Care
(SIAARTI) issued a modification of triage protocol and clinical ethics recommendations to guide Italian physicians for COVID-19 pandemic: "For the allocation of intensive care treatments, in exceptional, resource-limited circumstances" (60). At present, desperate attempts are being taken with both non-pharmacological and pharmacological interventions, including lockdown of the whole Italy in order to bring an immediate halt to the community transmission.

\section{Possible reasons for demographical variation of COVID-19 amongst Asian, European, American continent}

As COVID-19 is evolving across the globe, we are noticing variations in the infection rate, mortality, worst hit age group, disease response and so on (Table 2) (23,61-69). Initial reports from China suggested a median basic reproduction number (R0) of 2.79 , however R0 have been reported as high as $5.7(70,71)$. Deshwal et al. accumulated a 7-day data for all the new COVID-19 cases did a comparative study comparative study of Asian, European, and American continental countries (72).

Amongst the Asian countries, COVID-19 incidence in China has remained almost constant for almost last few 
Table 2 Geographical variation in the mortality reported as mentioned in various recently conducted studies

\begin{tabular}{lcc}
\hline Author & $\begin{array}{c}\text { Geographical location of conducting study North/South } \\
\text { America Asia Europe }\end{array}$ & Reported mortality or case fatality rate \\
\hline Borba et al. (61) & North/South America & $15-39 \%$ \\
Arentz et al. (62) & North/South America & Up to $67 \%$ \\
Basu A. (63) & North/South America & $1.7-33.3 \%$ \\
Zhou et al. (23) & Asia & Up to $28.2 \%$ \\
Wu et al. (64) & Asia & $2.3-49.0 \%$ \\
Yang et al. (65) & Asia & Up to $61.5 \%$ \\
Odone et al. (66) & Europe & $6.4-18.3 \%$ \\
La Maestra et al. (67) & Europe & $10-19 \%$ \\
Livingstone et al. (68) & Europe & $7.2 \%$ \\
Grasselli et al. (69) & Europe & Up to $26 \%$ \\
\hline
\end{tabular}

weeks. Cases in other Asian countries like India are on rising trend with evidence of community transmission. Italy, Spain, France, United Kingdom and Netherlands are the worst hit European countries. As per the report by Deshwal et al., ratio of confirmed cases, death cases and death rate per 1,000 confirmed cased were highest in North American countries and lowest in Asian countries (72).

There are multiple reasons which we could count on for variation in COVID-19 epidemiology; (I) community immunity; (II) travel and connectivity across the borders; (III) population density; (IV) social class disparities; (V) percentage of elderly population and so on. For instance, amongst the European nations, Italy has the oldest population, with approximately $23 \%$ of its citizens more than 65 years which probably was one of the major reasons for highest morality noted in Italy (73). Contrary to this, India which has so far done fairly well despite being the second most populous nation has more than $50 \%$ and $65 \%$ of its population below 25 years and below the age of 35 years respectively.

Another important factor that needs discussion is the variation in the differing strategies used for SARS-CoV-2 RT-PCR testing. This could be another potential factor for difference in country-specific case-fatality rates. For example, Korea adopted the strategy of liberal testing for SARS-CoV-2, that way many patients with milder disease or symptomatic disease were included in the denominator (74). In contrast, Italy prioritized testing for patients with more severe symptoms. This could be another reason for a higher case-fatality rate in Italy as compared with Korea $(7.2 \% v s$.
$1.0 \%)$. In United States, there is huge variation amongst the variation states as every state is following its own protocol as there is no declaration of nationwide lockdown (75).

\section{Management strategies}

\section{Non-pharmaceutical interventions (NPIs)}

Unfortunately, unlike many other diseases, we still are still away from the target antiviral drug and vaccine for SARS-CoV-2 infection. The prime importance of NPIs like social distancing, staying in home, work from home, self-monitoring, public awareness, self-quarantine etc. are constantly being emphasized by CDC, WHO, health ministries of all countries and social media houses (Figure 3). As SARS-CoV-2 infection can easily be transmitted through respiratory droplets and direct contact, the best way to halt the community transmission is to follow the civic etiquettes and social distancing. Neil M Ferguson and colleagues from Imperial College London recently submitted their report on the behalf of Imperial College COVID-19 Response Team (76). They studied the epidemiological modelling microsimulation model on COVID-19 for two countries: the UK (Great Britain specifically) and the US and they also suggested NPIs in their conclusion.

\section{Pharmacological interventions: newer strategies and developments}

\section{Supportive therapy}

Currently, Physicians across the world are testing for 


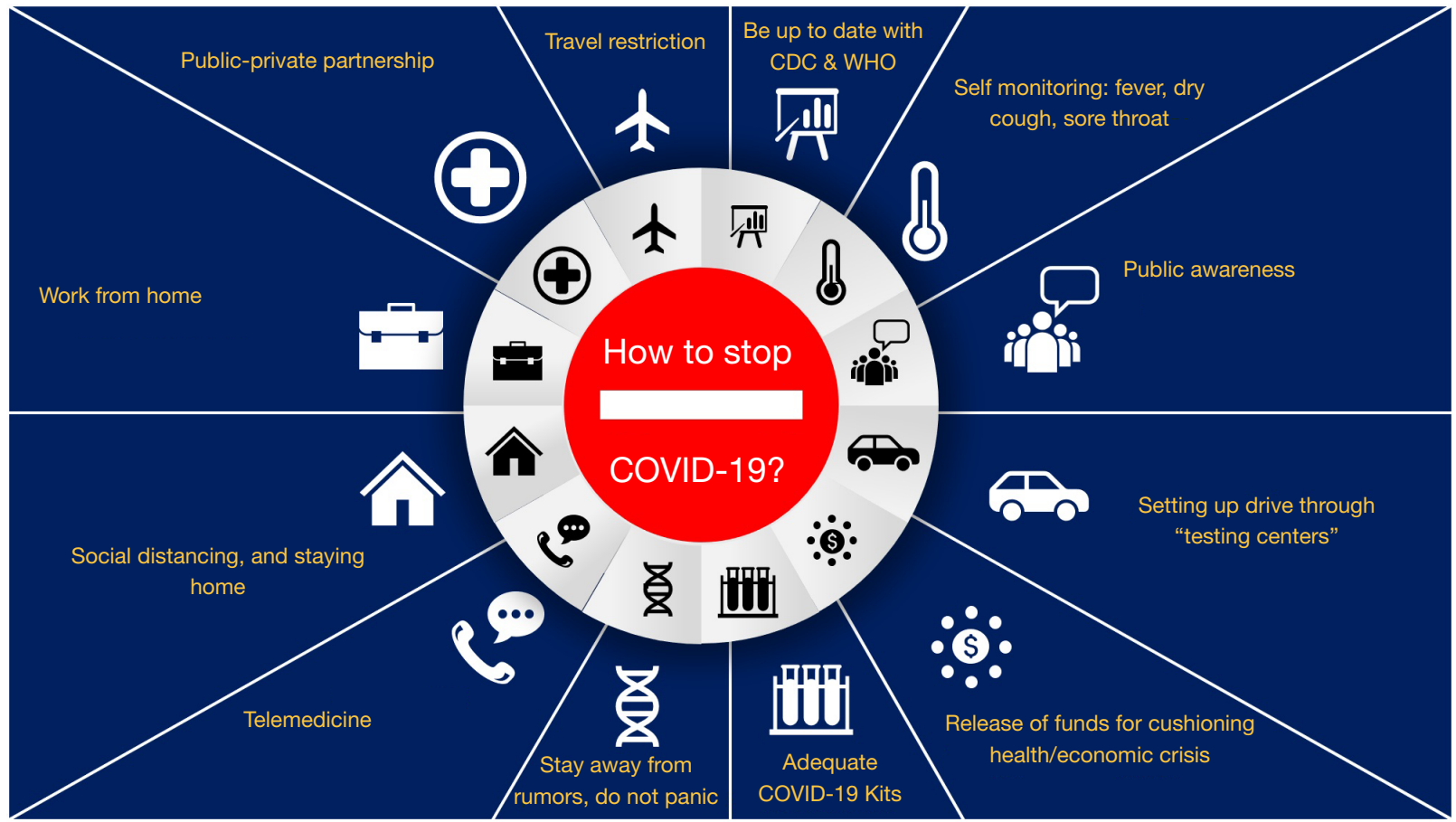

Figure 3 Pictorial representation of the expected non-pharmacological interventions and decisive actions required by the administration to stop COVID-19.

COVID with RTPCR testing for patients presenting with respiratory symptoms. It is particularly important to recognise the importance of keeping in mind the other local endemic disease like malaria, dengue, and so on (77). Similarly, the common cardiopulmonary diseases like congestive heart failure, community acquired pneumonia, pulmonary thromboembolism, COPD asthma exacerbation are few of the common differentials that need simultaneous testing and exclusion (78).

Once confirmed, the standard of care of the treatment of COVID-19 struck patients involves supportive care that includes adequate oxygenation, blood pressure support, and if needed the life support systems like invasive ventilation, Extracorporeal membrane oxygenations (ECMOs) and renal replacement therapy as needed. There is no approved antiviral drug for COVID-19. Worldwide, in a desperate attempt to save lives, doctors have been trying conventional antiviral agents like oseltamivir, lopinavir/ritonavir combination with variable results. Cao et al. studied effectiveness of Lopinavir-Ritonavir drug combination and randomised their 199 COVID-19 patients to the lopinavir-ritonavir group (99 patients) versus standardcare group (100 patients) (79). They did not find any benefit of using lopinavir-ritonavir over standard care with regards to time to clinical improvement, duration of oxygen therapy, duration of hospitalization, and time from randomization to death. However, they did find a shorter ICU stay (median, 6 vs. 11 days), a shorter hospital stay from date of randomisation (median, $12 v s .14$ days), and a higher percentage of clinical improvement at day 14 (45.5\% vs. $30.0 \%$ ) in the lopinavir-ritonavir group than in the standard-care group. However, all these benefits were nonsignificant between the two groups.

\section{Newer antiviral agents}

Recently National Medical Products Administration of China, China approved first anti-viral drug, Favilavir against COVID-19 (80). Another drug, named remdesivir which is a nucleoside analogue and originally developed during the Ebola outbreak is being studied at Nebraska medical centre, Omaha for its effectiveness in COVID-19 (81).

\section{Other drugs}

Anti-malarial agent, hydroxychloroquine (HCQ), an analogue of chloroquine is also commonly used in rheumatoid arthritis, lupus, Q fever, and Whipple's disease. It has recently gained limelight for its anecdotal reports of effectiveness in COVID-19 patients $(82,83)$. Doing 
clinical trials on humans was based on the vitro studies that showed an anti-SARS-CoV activity for HCQ (84). Gautret et al. studied the effectiveness of combination of HCQ and azithromycin versus HCQ alone versus standard care (twenty patients in total). The dose used in this study was oral HCQ $200 \mathrm{mg}$ three times a day for 10 days (83). The primary endpoint was to evaluate for virologic clearance at day-6 post-inclusion which showed a significant reduction of the viral carriage in the combination group than control group. The small patient number is the major limitation of the study but has given a good platform to work. The Food and Drug Administration (FDA) is currently investigating if $\mathrm{HCQ}$ can reduce the symptom duration, or "viral shedding", which might be helpful in mitigating the disease spread (85). Recently, there has been conflicting reports on the use of cardiac medications like ACE inhibitors, ARB's, and other RAAS antagonists on patients with COVID-19. For instance, Goldstein et al. suggested that use of ARB might facilitate the viral entry by increasing the expression of ACE 2 receptors. However, this needs confirmation by conducting larger studies (86-88).

\section{Investigational vaccines}

Development of vaccine is a tedious and time taking process. NIH has initiated a clinical trial at Kaiser Permanente Washington Health Research Institute (KPWHRI) in Seattle (89). This trial involves 45 volunteers who will be receiving an investigational vaccine (mRNA1273), two sessions of injections over 28 days apart. These patients will be subsequently followed for vaccine's potency. Unfortunately, the result will be available approximately after a year.

\section{Revisiting old therapy: using convalescent serum for COVID-19 susceptible population}

Immunologists at John Hopkins centre are working on setting up a lab which aims for using the concept of taking the serum from the patients who have recovered from COVID-19 disease and injecting them to the individuals who have high susceptibility to acquire infection, vulnerable population like old individuals, and health care providers who are always at high risk of acquiring the infection $(90,91)$.

\section{Conclusions}

COVID-19 pandemic has already costed lives of more than 250,000 individuals, mostly elderly and fragile population. This is time of introspection and learning from our mistakes. Psychological wellness of front-line workers and rest of the healthcare team is another consideration that should not be ignored during these times (92-95), and countries like China and South Korea who were initially the most hit countries could contain the disease spread by liberal testing of their population, stringent quarantine of people under investigation and isolation of the positive cases. Rest of the countries need to act urgently as well to bring an immediate halt in the community transmission. Also, this is an evolving pandemic, the literature regarding therapeutics and strategies to monitor the trajectory are still evolving. Our manuscript highlights the importance of the above two point. This review, in no way is a complete guide to the management and public health policy but an overview.

\section{Acknowledgments}

Funding: None.

\section{Footnote}

Peer Review File: Available at http://dx.doi.org/10.21037/ atm-20-2793

Conflicts of Interest: All authors have completed the ICMJE uniform disclosure form (available at http://dx.doi. org/10.21037/atm-20-2793). AL serves as an unpaid section editor for Annals of Translational Medicine from Nov 2019 to Oct 2021.The other authors have no conflicts of interest to declare.

Ethical Statement: The authors are accountable for all aspects of the work in ensuring that questions related to the accuracy or integrity of any part of the work are appropriately investigated and resolved. All authors have participated in the preparation of this manuscript and have approved the final version.

Open Access Statement: This is an Open Access article distributed in accordance with the Creative Commons Attribution-NonCommercial-NoDerivs 4.0 International License (CC BY-NC-ND 4.0), which permits the noncommercial replication and distribution of the article with the strict proviso that no changes or edits are made and the original work is properly cited (including links to both the formal publication through the relevant DOI and the license). See: https://creativecommons.org/licenses/by-nc-nd/4.0/. 


\section{References}

1. Sahu KK, Lal A, Mishra AK. Latest updates on COVID-2019: A changing paradigm shift. J Med Virol 2020. [Epub ahead of print].

2. Sahu KK, Mishra AK, Lal A. Comprehensive update on current outbreak of novel coronavirus infection (2019nCoV). Ann Transl Med 2020;8:393.

3. Available online: https://www.worldometers.info/ coronavirus/country/italy/

4. Li Q, Guan X, Wu P, et al. Early Transmission Dynamics in Wuhan, China, of Novel Coronavirus-Infected Pneumonia. N Engl J Med 2020;382:1199-207.

5. Chinazzi M, Davis JT, Ajelli M, et al. The effect of travel restrictions on the spread of the 2019 novel coronavirus (COVID-19) outbreak. Science 2020;368:395-400.

6. Available online: https://www.cdc.gov/coronavirus/2019ncov/prepare/transmission.html

7. Lal A, Davaro R, Mishra AK, et al. Detection of coexisting toxigenic Clostridium difficile and nontyphoidal Salmonella in healthcare worker with diarrhea: A therapeutic dilemma. J Family Med Prim Care 2019;8:2724-7.

8. Wang D, Hu B, Hu C, et al. Clinical Characteristics of 138 Hospitalized Patients With 2019 Novel Corona-virusInfected Pneumonia in Wuhan, China. JAMA. Published online February 07, 2020. doi:10.1001/jama.2020.1585.

9. Huang C, Wang Y, Li X, et al. Clinical features of patients infected with 2019 novel coronavirus in Wuhan, China. Lancet 2020;395:497-506.

10. Available online: https://www.cdc.gov/mmwr/volumes/69/ wr/mm6912e2.htm?s_cid=mm6912e2_w

11. Lal A, Akhtar J, Ullah A, et al. First Case of Pleural Empyema Caused by Staphylococcus simulans: Review of the Literature. Case Rep Infect Dis 2018;2018:7831284.

12. Lal A, Akhtar J, Khan MS, et al. Primary endobronchial amyloidosis: A rare case of endobronchial tumor. Respir Med Case Rep 2018;23:163-6.

13. Lal A, Mishra AK, Sahu KK, et al. Spontaneous Pneumomediastinum: Rare Complication of Tracheomalacia. Arch Bronconeumol 2020;56:185-6.

14. Upadhyay J, Trivedi N, Lal A. Risk of Future Type 2 Diabetes Mellitus in Patients Developing Steroid-Induced Hyperglycemia During Hospitalization for Chronic Obstructive Pulmonary Disease Exacerbation. Lung 2020;198:525-33.

15. Lal A, Pena ED, Sarcilla DJ, et al. Ideal Length of Oral Endotracheal Tube for Critically Ill Intubated Patients in an Asian Population: Comparison to Current Western
Standards. Cureus 2018;10:e3590.

16. Lal A, Nabzdyk C, Ramakrishna H, et al. Consider Heightened Awareness of Propofol Infusion Syndrome after Extracorporeal Membrane Oxygenation (ECMO) Decannulation. J Cardiothorac Vasc Anesth 2019. [Epub ahead of print].

17. Sahu KK, Siddiqui AD, Cerny J. Managing Sickle Cell Patients With COVID-19 Infection: The Need to Pool Our Collective Experience. Br J Haematol 2020. [Epub ahead of print].

18. Sahu KK, Siddiqui AD, Cerny J. COVID-19 pandemic and impact on hematopoietic stem cell transplantation. Bone Marrow Transplant 2020. [Epub ahead of print].

19. Sahu KK, Jindal V, Siddiqui AD, et al. Facing COVID-19 in the hematopoietic cell transplant setting: A new challenge for transplantation physicians. Blood Cells Mol Dis 2020;83:102439.

20. Lal A, Davis MJ, Akhtar J, et al. Serious Cover-Up: Hodgkin's Lymphoma Masked by Organizing Pneumonia. Am J Med 2018;131:1174-7.

21. Sahu KK, Mishra AK, Lal A. Novel coronavirus (2019$\mathrm{nCoV}$ ): Update on 3rd Coronavirus Outbreak of 21st Century. QJM 2020;113:384-6.

22. Mo P, Xing Y, Xiao Y, et al. Clinical characteristics of refractory COVID-19 pneumonia in Wuhan, China. Clin Infect Dis 2020. doi: 10.1093/cid/ciaa270.

23. Zhou F, Yu T, Du R, et al. Clinical course and risk factors for mortality of adult inpatients with COVID-19 in Wuhan, China: a retrospective cohort study. Lancet 2020;395:1054-62.

24. Sahu KK, Lal A, Mishra AK. COVID-2019 and Pregnancy: A plea for transparent reporting of all cases. Acta Obstet Gynecol Scand 2020. [Epub ahead of print].

25. Sahu KK, Mishra AK, Lal A. Re: From the frontlines of COVID-19-How prepared are we as obstetricians: A commentary. BJOG 2020. [Epub ahead of print].

26. Sahu KK, Mishra AK, Lal A. A twin challenge to handle: COVID-19 with pregnancy. J Med Virol 2020. [Epub ahead of print].

27. Lal A, Akhtar J, Pinto S, et al. Recurrent Pulmonary Embolism and Hypersensitivity Pneumonitis Secondary to Aspergillus, in a Compost Plant Worker: Case Report and Review of Literature. Lung 2018;196:553-60.

28. Akella P, Loganathan S, Jindal V, et al. Anti PD-1 immunotherapy related interstitial lung disease presenting as respiratory failure - A review with case series. Respir Med Case Rep 2018;26:17-22.

29. Special Expert Group for Control of the Epidemic of 
Novel Coronavirus Pneumonia of the Chinese Preventive Medicine Association. An update on the epidemiological characteristics of novel coronavirus pneumonia (COVID-19). Zhonghua Liu Xing Bing Xue Za Zhi 2020;41:139-44.

30. Available online: https://www.fda.gov/media/134922/ download

31. Sahu KK, Dhibar DP, Varma S, et al. CML with pregnancy: real challenges in developing nations. Leuk Lymphoma 2017;58:1518-9.

32. Sahu KK, Varma SC. Herpes zoster complicating bortezomib therapy. Indian J Med Res 2015;141:247-8.

33. Sahu KK, Prakash G, Khadwal A, et al. A Rare Case of Hemorrhagic Cystitis in Allogeneic Hematopoietisac Stem Cell Transplant Patient. Indian J Hematol Blood Transfus 2016;32:196-200.

34. Lal A, Abraham GM. Utility of CD4 Cell Count and Viral Load Assay in Hospitalized Patients with Known HIV Infection: High Value Care Exercise. Infect Disord Drug Targets 2019. [Epub ahead of print].

35. Sahu KK, Mishra AK, Lal A, et al. Mycobacterium Avium Complex: A Rare Cause of Pancytopenia in HIV Infection. J Microsc Ultrastruct 2019;8:27-30.

36. Mishra AK, Lal A, Sahu KK, et al. Mechanisms of neurological injury in COVID -19. World Neurosurg 2020. [Epub ahead of print].

37. Asadi-Pooya AA, Simani L. Central nervous system manifestations of COVID-19: A systematic review. J Neurol Sci 2020;413:116832.

38. Mishra AK, Sahu KK, George AA, et al. A review of cardiac manifestations and predictors of outcome in patients with COVID - 19. Heart Lung 2020. doi: 10.1016/j.hrtlng.2020.04.019.

39. Mishra AK, Sahu KK, Lal A, et al. Patterns of heart Injury in COVID - 19 and relation to outcome. J Med Virol 2020. [Epub ahead of print].

40. Sahu KK, Siddiqui AD. From Hematologist's desk: The effect of COVID-19 on the blood system. Am J Hematol 2020. [Epub ahead of print].

41. Sahu KK, Jindal V, Siddiqui AD. Managing COVID-19 in Patients With Cancer: A Double Blow for Oncologists. JCO Oncol Pract 2020;16:223-5.

42. Centers for Disease Control and Prevention. The CDC guide to COVID-19. Available online: https://www.cdc. gov/coronavirus/2019-ncov/index.html

43. Lal A, Mishra AK, Sahu KK. CT chest findings in coronavirus disease-19 (COVID-19). J Formos Med Assoc 2020;119:1000-1.
44. Sahu KK, Mishra AK, Lal A. An Update on CT Chest Findings in Coronavirus Disease-19 (COVID-19). Heart Lung 2020. [Epub ahead of print].

45. Ai T, Yang Z, Hou H, et al. Correlation of chest CT and RT-PCR testing in Coronavirus Disease 2019 (COVID-19) in China: a report of 1014 cases. Radiology 2020. [Epub ahead of print].

46. Fang Y, Zhang H, Xie J, et al. Sensitivity of Chest CT for COVID-19: Comparison to RT-PCR. Radiology 2020. [Epub ahead of print].

47. Guan WJ, Ni ZY, Hu Y, et al. China Medical Treatment Expert Group for Covid-19. Clinical Characteristics of Coronavirus Disease 2019 in China. N Engl J Med 2020;382:1708-20.

48. Bernheim A, Mei X, Huang M, et al. Chest CT Findings in Coronavirus Disease-19 (COVID-19): Relationship to Duration of Infection. Radiology 2020;295:200463.

49. Lal A, Akhtar J, Jindal V, et al. Rare Cause of Respiratory Failure: A Twist in the Tale. Ann Am Thorac Soc 2018;15:880-3.

50. Lal A, Mishra AK, Sahu KK. Is EVALI the new scapegoat for every abnormal chest imaging? Heart Lung 2020. [Epub ahead of print].

51. Lal A, Akhtar J, Isaac S, et al. Unusual cause of chest pain, Bornholm disease, a forgotten entity; case report and review of literature. Respir Med Case Rep 2018;25:270-3.

52. Lal A, Mishra AK, Sahu KK. Vitamin E Acetate and E-Cigarette or Vaping Product-Associated Lung Injury (EVALI): An Update. Am J Med 2019. [Epub ahead of print].

53. Sahu KK, Badhala P, Malhotra P, et al. A rare case of rituximab induced interstitial lung disease. Lung India 2016;33:472-3.

54. Horowitz J. Italy's health care system groans under coronavirus - a warning to the world. New York Times. March 12, 2020. Available online: https://www.nytimes. com/2020/03/12/world/europe/12italy-coronavirushealth-care.html. opens in new tab

55. Remuzzi A, Remuzzi G. COVID-19 and Italy: what next? Lancet 2020;395:1225-8.

56. Available online: http://www.salute.gov.it/portale/ nuovocoronavirus/dettaglioContenutiNuovoCoronavirus. jsp?lingua $=$ italiano $\&$ id $=5351 \&$ area $=$ nuovoCoronavirus $\& \mathrm{~m}$ enu=vuoto

57. Rosenbaum L. Facing Covid-19 in Italy - Ethics, Logistics, and Therapeutics on the Epidemic's Front Line. N Engl J Med 2020;382:1873-5.

58. Grasselli G, Pesenti A, Cecconi M. Critical Care 
Utilization for the COVID-19 Outbreak in Lombardy, Italy: Early Experience and Forecast During an Emergency Response. JAMA 2020. [Epub ahead of print].

59. Young BE, Ong SWX, Kalimuddin S, et al. Epidemiologic features and clinical course of patients infected with SARSCoV-2 in Singapore. JAMA 2020;323:1488-94.

60. Riccioni L, Bertolini G, Giannini A, et al. Clinical ethics recommendations for the allocation of intensive care treatments, in exceptional, resource-limited circumstances. Recenti Prog Med 2020;111:207-11.

61. Borba MGS, Val FFA, Sampaio VS, et al. Effect of High vs Low Doses of Chloroquine Diphosphate as Adjunctive Therapy for Patients Hospitalized With Severe Acute Respiratory Syndrome Coronavirus 2 (SARS-CoV-2) Infection: A Randomized Clinical Trial. JAMA Netw Open 2020;3:e208857.

62. Arentz M, Yim E, Klaff L, et al. Characteristics and Outcomes of 21 Critically Ill Patients With COVID-19 in Washington State. JAMA 2020;323:1612-4.

63. Basu A. Estimating The Infection Fatality Rate Among Symptomatic COVID-19 Cases In The United States. Health Aff (Millwood) 2020. [Epub ahead of print].

64. Wu Z, McGoogan JM. Characteristics of and Important Lessons From the Coronavirus Disease 2019 (COVID-19) Outbreak in China: Summary of a Report of 72314 Cases From the Chinese Center for Disease Control and Prevention. JAMA 2020;323:1239-42.

65. Yang X, Yu Y, Xu J, et al. Clinical course and outcomes of critically ill patients with SARS-CoV-2 pneumonia in Wuhan, China: a single-centered, retrospective, observational study. Lancet Respir Med 2020;8:475-81.

66. Odone A, Delmonte D, Scognamiglio T, et al. COVID-19 deaths in Lombardy, Italy: data in context. Lancet Public Health 2020. [Epub ahead of print].

67. La Maestra S, Abbondandolo A, De Flora S. Epidemiological trends of COVID-19 epidemic in Italy during March 2020. From 1,000 to 100,000 cases. J Med Virol 2020. [Epub ahead of print].

68. Livingston E, Bucher K. Coronavirus Disease 2019 (COVID-19) in Italy. JAMA 2020;323:1335.

69. Grasselli G, Zangrillo A, Zanella A, et al. Baseline Characteristics and Outcomes of 1591 Patients Infected With SARS-CoV-2 Admitted to ICUs of the Lombardy Region, Italy. JAMA 2020;323:1574-81.

70. Liu Y, Gayle AA, Wilder-Smith A, et al. The reproductive number of COVID-19 is 429 higher compared to SARS coronavirus. J Travel Med 2020;27:taaa021.

71. Sanche S, Lin YT, Xu C, et al. High Contagiousness and
Rapid Spread of Severe Acute Respiratory Syndrome Coronavirus 2. Emerg Infect Dis 2020. [Epub ahead of print].

72. Deshwal VK. COVID 19: A Comparative Study of Asian, European, American continent. Int J Sci Res Engineer Dev 2020;3:436.

73. Onder G, Rezza G, Brusaferro S. Case-Fatality Rate and Characteristics of Patients Dying in Relation to COVID-19 in Italy. JAMA 2020. [Epub ahead of print].

74. Coronavirus disease 2019 (COVID-19): situation report-57. Published March 17, 2020. Accessed March 18, 2020. Available online: https://www.who.int/docs/defaultsource/coronaviruse/situation-reports/20200317-sitrep57-covid-19.pdf?sfvrsn=a26922f2_2

75. Sahu KK, Kumar R. Current perspective on pandemic of COVID-19 in the United States. J Family Med Prim Care 2020;9:1784-91.

76. Available online: https://www.imperial.ac.uk/media/ imperial-college/medicine/sph/ide/gida fellow-ships/ Imperial-College-COVID19-NPI-modelling-16-03-2020. pdf

77. Lam LTM, Chua YX, Tan DHY. Roles and challenges of primary care physicians facing a dual outbreak of COVID-19 and dengue in Singapore. Fam Pract 2020. [Epub ahead of print].

78. Sahu KK, Mishra AK, Martin K, et al. COVID-19 and clinical mimics. Correct diagnosis is the key to appropriate therapy. Monaldi Arch Chest Dis 2020;90. [Epub ahead of print].

79. Cao B, Wang Y, Wen D, et al. A Trial of LopinavirRitonavir in Adults Hospitalized with Severe Covid-19. N Engl J Med 2020;382:1787-99.

80. Available online: https://www.clinicaltrialsarena.com/news/ china-approves-favilavir-covid-19/

81. Available online: https://www.nih.gov/news-events/newsreleases/nih-clinical-trial-remdesivir-treat-covid-19-begins

82. Available online: https://www.mediterranee-infection.com/ hydroxychloroquine-and-azithromycin-as-a-treatment-ofcovid-19/

83. Gautret P, Lagier JC, Parola P, et al. Hydroxychloroquine and azithromycin as a treatment of COVID-19: results of an open-label non-randomized clinical trial. Int J Antimicrob Agents 2020. [Epub ahead of print].

84. Biot C, Daher W, Chavain N, et al. Design and synthesisof hydroxyferroquine derivatives with antimalarial and antiviral activities. J Med Chem 2006;49:2845-9.

85. Available online: https://www.axios.com/coronavirustreatment-chloroquine-trump-administration-fc $515 \mathrm{c} 96$ - 
9ab8-4bfa-bfac-9b8df6715cbc.html

86. Mishra AK, Sahu KK, Lal A. Reporting of all cardiac medications and their outcome in COVID - 19. J Med Virol 2020. [Epub ahead of print].

87. Goldstein MR, Poland GA, Graeber CW. Are certain drugs associated with enhanced mortality in COVID-19? QJM 2020. [Epub ahead of print].

88. Mishra AK, Sahu KK, Sargent J. Cardiac drugs and outcome in COVID - 19. QJM 2020. [Epub ahead of print].

89. Available online: https://www.nih.gov/news-events/newsreleases/nih-clinical-trial-investigational-vaccine-covid19-begins

90. Available online: https://www.sciencealert.com/a-classictherapy-from-the-1890s-could-help-protect-againstcoronavirus-experts-say

91. Sahu KK, Jindal V, Siddiqui AD, et al. Convalescent

Cite this article as: Sahu KK, Mishra AK, Lal A. Trajectory of the COVID-19 pandemic: chasing a moving target. Ann Transl Med 2020;8(11):694. doi: 10.21037/atm-20-2793
Plasma Therapy: A Passive Therapy for An Aggressive COVID-19. J Med Virol 2020. [Epub ahead of print].

92. Tan BYQ, Chew NWS, Lee GKH, et al. Psychological Impact of the COVID-19 Pandemic on Health Care Workers in Singapore. Ann Intern Med 2020:M20-1083.

93. Lal A, Mishra AK, Thapa SS. Teamwork in Medicine. N Engl J Med 2019;380:2281.

94. Lal A, Tharyan A, Tharyan P. The prevalence, determinants and the role of empathy and religious or spiritual beliefs on job stress, job satisfaction, coping, burnout, and mental health in medical and surgical faculty of a teach-ing hospital: A cross-sectional survey. Rev Med Interne 2020;41:232-40.

95. Pfefferbaum B, North CS. Mental Health and the Covid-19 Pandemic. N Engl J Med 2020. [Epub ahead of print]. 